\title{
The system of formation of the readiness of future foreign language teachers for the use of technological innovations
}

\author{
O. O. Osova \\ Municipal institution "Kharkiv Humanitarian-Pedagogical Academy" of Kharkiv Regional Council \\ Corresponding author. E-mail: osova.olga@gmail.com
}

Paper received 30.01.19; Accepted for publication 08.01.19.

\section{https://doi.org/10.31174/SEND-PP2019-188VII77-10}

\begin{abstract}
Osova O.O. The system of formation of the readiness of future foreign language teachers for the use of technological innovations. On the basis of the analysis of scientific and pedagogical sources in the article the necessity of creating a system of formation of the readiness of future foreign language teachers for technological innovations was substantiated. The characteristic features of the system (integrity, structure, hierarchy, interdependence of system and environment, plurality of descriptions) were educed and its basic structural components were defined: motivational organizational, semantic, procedural and effectively-estimate.

Keywords: system, readiness, foreign language teacher, technological innovations, system components.
\end{abstract}

Modern pedagogical science and practice in the field of pedagogical education face a difficult task of preparing foreign language teachers to use innovative learning technologies in the context of smart education. Future teachers of a foreign language must be prepared to perform complex professional functions in the context of pliant learning that takes place in an interactive educational environment. Thus, the level of professionalism of the future teacher of a foreign language is directly dependent on the level of formation of its readiness for the implementation of innovative learning technologies in the conditions of 'smart education'.

The formation of the readiness of future foreign language teachers to implement innovative learning technologies in terms of smart education provides in the first instance organization of grasping the sum of knowledge and skills regarding mastery of multidimensional technologies to introduce them to the process of teaching a foreign language.

Theoretical analysis of the problem gives grounds for evidence of a wide range of scientific research, the results of which serve as the basis for further research. Various aspects of the introduction of innovative technologies in professional activity found their visibility in the works of such scientists: theoretical issues of educational innovation (L. Husak, L. Danylenko, I. Dychkivska S. Sysoieva M. Chepil, A. Shapran, L. Shtephan and others) ; the introduction of pedagogical technologies in higher educational institutions (L. Budanova, O. Ionova, V. Palamarchuk, A. Piekhota, G. Ponomareva, G. Selevko and others). Scientists noticed the formation of readiness of the teacher to innovative activity (M. Anisimov, O. Biliakovska, I. Havrysh, O. Honcharova, T. Demydenko O. Dubaseniuk, N. Klokar, K. Makahon, T. Perekrostova, L. Petrychenko , V. Uruskyi, I. Shorobura and others). The use of innovative educational systems and innovative technologies in the process of teaching teacher's teaching has been given attention in the works of A. Aleksiuk, V. Bespalka, M. Vasylieva, B. Hershunskyi, V. Hrynova, V. Yevdokymov, V. Lozova, A. Malykhin, A. Nisimchuk, I. Osadchenko, O. Padalka, I. Podlasyi, I. Prokopenko, B. Skinner, S. Spoldynh and others.

The problem of professional training of future teachers of foreign languages through innovative pedagogical technologies was facilitated by the scientific achieve- ments of O. Honcharova, Y. Zhyliaieva, L. Morska, Y. Polat and others.

However, there is no complex, holistic, systemic investigation of the problem that has caused the goal of our article - to substantiate the components of the system of forming the readiness of future teachers of a foreign language for technological innovations.

The following research methods were used to address this goal: retrospective analysis; abstraction, concretization and generalization of theoretical positions for the analysis of the scientific research thesaurus; theoretical analysis, synthesis, systematization of sources to form scientific apparatus, formulation of basic concepts, structure and synthesis to study the structural components of the system, a comprehensive analysis of the content, forms and methods of innovative educational practices to develop theoretical foundations of innovative technologies of teaching foreign languages.

In teaching science formation of future foreign language teachers to implement innovative learning technologies in the new environment "flexible learning" process is treated primarily as innovative professional development of the young man, becoming her under the influence of a combination of factors as the subject of innovative educational activities.

Despite the variety of approaches to the definition of the essence of the notion of "system", it should be noted that from which positions the authors of pedagogical studies did not consider this problem, it is obvious that its characteristics do not contradict each other, but are complementary and define it as a whole, consisting of a set of interconnected elements (components). The conducted scientific and pedagogical research allows to assert that the characteristic features of the system are integrity, structural, hierarchy, interdependence of system and environment, plurality of descriptions.

With the development of a systematic approach in the methodology of scientific knowledge, the term "pedagogical system" appears. In the course of the study, it was discovered that several references to the development of the systematic approach to the pedagogical process were identified in the scientific literature: as a set of interconnected elements (components) (I. Vasyliev, O. Kovalov, N. Kuzmina, etc.); on the basis of isolating the integrity as an essential feature of the system (V. Bespalko, V. Volodko, T. Shamova, etc.). 
On the basis of taking into account existing pedagogical science approaches to the essence of the pedagogical system and its details in the context of our study, we use the notion "the system of forming the readiness of future teachers of a foreign language for the implementation of innovative learning technologies in the context of smart education," which is defined as a set of interrelated educational components that gradually change each other.

The main structural components of the system of forming the readiness of future foreign language teachers for the implementation of innovative teaching technologies in the context of smart education include target, organizational and motivational, content-related, procedural and productive and evaluative.

As noted by researchers [1], the backbone factor is the purpose of the pedagogical system, which determines the choice of content and organization of education, therefore an important component of the pedagogical system is the target one. In accordance with the theory of goal setting, one of the decisive factors in human behavior is the development goal which a person has. The effectiveness of achieving the eventual result depends on the complexity of the goal, which determines the level of professionalism and singularity of the goal, which determines the degree of importance of the goal for a specialist. Accordingly, it is necessary to conduct such a targeted modeling of the pedagogical system of formation of the readiness of future foreign language teachers for the implementation of innovative learning technologies in the context of smart education, which would provide opportunities and wishes for their achievement. In the context of our study, the strategic aim is defined as "an ideal, consciously planned form of the result of the educational process in relation to the of actions and conditions that cause it" [6, p. 29]. The result of our developed pedagogical system was the formation of the readiness of future foreign language teachers for the implementation of innovative technologies of teaching foreign languages in the context of smart education.

In our opinion, the leading component of the proposed system is organizational and motivational one, because it directly affects all other components and represents the "foundation" of the system.

Only if there are internal motives that ensure future foreign language teachers' formation of values-based attitude towards the implementation of innovative learning technologies and stimulate the students' interest in innovative technologies, the need for study and introduction of innovative experience in the context of smart education will be formed. The definition of internal conditions is driven by the need to take into account the leading regulator of any activity: "motive-purpose" [3]. Psychopedagogical science (L. Bozhovych, E. Zeier, E. Ilin, A. Markova, L. Slavina and others) proved that the process of goal-setting is deeply personal and requires taking into account those stimulus motives, student's life prospects, that perform the role of the backbone factor relatively to other motives of educational activity.

However, the control of a student's motives, which is carried out on the basis of his personal and psychological characteristics, opens possibilities for a deliberate evaluation of its capabilities and directs him the choose his individual trajectory in the organization of innovative professional activity in terms of smart education.
In view of the above, the formation of future foreign language teachers' values-based attitude towards the introduction of innovative learning technologies should be aimed at stimulating internal motives arising from the awareness of the contradiction among the knowledge, skills and abilities that they already possess, and the need to acquire new, more mobile. Resolving this contradiction provides the inclusion of students in an active learning process, promotes professional interest, stimulates mastering skills of goal-setting, design, control and evaluation, reflexive and affect performance at all stages of teaching and learning activity.

The organizational and motivational component is also connected with the availability and taking into account the level of material and technical basis for the formation of the readiness of future teachers for the implementation of innovative learning technologies in the context of smart education: informatization and mediatization of library resources of higher educational institutions, technical equipment of special cabinets, the presence of interactive platform provide the availability of innovative infrastructure (electronic libraries, institutional repositories, media libraries, etc.); special cabinets, equipped with a set of software and hardware training resources( lingaphone laboratories, interactive offices, etc.); supporting of the teacher's workplace in the educational and scientific media space; providing the access for teachers and students to the telecommunication networks (Internet, URAN, etc.).

The creation of multidimensional scientific-research environment is promoted by the use of multimedia that provides transportation of educational and research materials by means of e-mail, web, electronic delivery of documents, services of file transfer, etc; organization of access to multimedia editions by means of network technologies, the Internet; holding seminars, conferences, communicating in real time, etc.

Thus, in the conditions of smart education precisely mediatization provides the combination of different types of textual, graphic, audio, video information and a variety of means for their creating, submitting or extracting them, mediatization becomes not only a necessary element of material and technical provision of higher education institutions, but also a core of virtual, innovative education.

An important component of the system of formation of the readiness of future foreign language teachers for the use of technological innovations is a content component, which involves the availability of future foreign language teachers' set of knowledge about the essence and structure of innovative teaching technologies, their types, knowledge of effective methods of their application for solving pedagogical tasks in conditions of smart education.

In the system developed by us, the effectiveness of the formation of the content component is ensured by the purposeful, systematic and consistent introduction into the educational process of subjects of cycles of professional training, disciplines of an independent choice of educational institution and disciplines of free choice of students of content elements of innovation, innovative teaching technologies, their types, which should ensure the formation of future readiness teachers of a foreign language to the implementation of innovative technology training, 
expanding their horizons, more profound penetration into the essence of the problem. Students are future foreign language teachers who can receive a system of knowledge on pedagogical innovation, innovative teaching technologies in the process of studying the disciplines necessary for future professional and pedagogical activity ("Pedagogy and Psychology of Higher School", "Fundamentals of Pedagogical Excellence", "Pedagogical Innovations and Methodology of Educational Work "," Modern Approaches to Teaching a Foreign Language "," Methods of Teaching a Foreign Language in High School ", etc.). Students' studying new information technologies of teaching, using pedagogical educational tools, controlling devices, computer networks and their capabilities; didactic possibilities of modern technical means of training and general methodical rules of their use; prospects of development and use of technical means of knowledge control, which takes place in the course of studying the course "New Information Technologies and Use of Technology in Education", etc.

In solving the task of creating a cognitive base for the formation of the readiness of future teachers of a foreign language to use technological innovation, a special role belongs to the course "Innovative approaches to teaching a foreign language", the results of which are:

- the presence of students with a broad theoretical basis that reveals the general and special regularities of the process of teaching a foreign language as a means of communication, education, upbringing, growth and intelligence which includes, in addition to methodological knowledge, knowledge in related to the methodology of sciences psychological and pedagogical and philological cycles, which allows to form an idea about the content and structure of the innovative pedagogical activity of a teacher, a teacher of a foreign language;

- the existence of a system of knowledge about the basic concepts, structure and patterns of the innovative pedagogical process, innovative technologies of teaching a foreign language, their types, which helps to form the basis of their skills to apply their knowledge in practice, taking into account specific conditions;

- the formation of theoretical knowledge that will help students to develop innovative thinking, which will promote future teachers, teachers of foreign language in solving various methodological problems arising in the innovative educational process.

The content, organizational and motivational components serve as a peculiar basis for the procedural component of the proposed system. Functional capabilities of the mentioned component considerably expand in the conditions of smart education by creating a learning linguistic environment, approximated by the authenticity and intensity of linguistic communication to real communication, the formation of skills and skills of students to organize and implement the implementation of innovative technologies of teaching foreign languages.

The procedural component involves the use of forms and methods of training aimed at the formation of future teachers of a foreign language as subjects of innovation activity. Based on scientific studies of scientists $[2,4 ; 7]$ and based on our own experience [5], the most effective forms and methods of preparing future teachers for the implementation of innovative learning technologies are educational discussions, role and business games, interactive methods, micro-testing, mini-competitions, brainstorming, trainings, problem and traditional lectures, project methods, reflexive teaching, work in groups, foreign language training exercises on the development of innovative skills, etc. All these methods are aimed at the formation of future teachers as subjects of innovation activity.

As it is known, the specifics of a foreign language as a subject of study requires the use of individual, individualgroup and group forms of organization of the process of preparing a student for innovation activity. Students need to be taught to use innovative learning technologies based on this specificity through familiarization with positive innovative experience of introduction of innovative technologies of teaching foreign languages, involvement in the creation of innovative projects, inclusion in active research activities, which in the future leads to the formation of the readiness of the future teacher of a foreign language to realization of technological innovations in the conditions of smart education.

It is proved that the efficiency of the functioning of the procedural component of the system provides various forms of training, in particular, the creation of professional and pedagogical situations that are revealed in the process of subject-subject interaction. One of the directions of orientation of future teachers to subject-subject interaction is the use of forms and methods of teaching, the leading features and tools of which are polygon, dialogue, interpersonal relations, the creation of a situation of success, positivity of evaluation, reflection, etc.

One of the ways to create intensive foreign language communication is through the introduction of dialogue technologies ("Swap places", "Completing the phrase", "Compliment", "Brainstorming", "Associative bush", "Hot chair", "Microphone", " Merry-Go-Round ", "Battleship", etc.). Procedural basis of the studies using these learning technologies is a 'communicative attack' organized by a teacher to involve students in foreign language communicative interaction. The involvement of interactive technologies helps to create an atmosphere of joint search and creativity in classes, as well as the development of all kinds of speech activity among students ("Picture Gallery", "Festive Cake", "6×6×6", "Carpet of Ideas", etc.).

The use of computer technologies (Internet resources, presentations, computer lectures, computer programs, blogs, video films, videos, mobile applications, etc.) is the basis of the organization of educational process in the smart society.

Their introduction in the system of forming the readiness of future teachers of a foreign language for the implementation of innovative learning technologies in the context of smart education, firstly, promotes the creation of a learning linguistic environment that approaches the authenticity and intensity of linguistic communication to real communication, and secondly, eliminates psychological difficulties speaking, developing spoken language skills, phonetic skills and media skills, and thirdly, provides an individualized learning style.

The system of forming of the readiness of future foreign language teachers for the use of technological innovations will not be integral with the absence of a produc- 
tive-evaluated component, since the functions of control and evaluation are important in the process of preparing future foreign language teachers. The indicated component involves the implementation of a set of diagnostic procedures in order to determine the degree of achievement of the overall goal - the formation of the readiness of future teachers of the foreign language to implement innovative learning technologies in the conditions of smart education, intermediate sections, analysis of results, if necessary, corrective measures, assessment of the effectiveness of the system by detecting the dynamics of indicators of readiness levels of future teachers of a foreign language for the implementation of innovative learning technologies in the conditions of smart- education. In order to assess the level of formation of the readiness of future foreign language teachers for the implementation of innovative technologies of teaching foreign languages, the following criteria were developed: motivational, content-activity, person-reflexive.
Taking into account the provision on the level of professional activity and taking into account L. Morska's system of training future teachers of a foreign language for the use of information technologies [4], L. Shtefan, a scientific and methodical system for the formation of the innovative culture of future engineer educators [7], I. Shumilova research and methodological system of formation of general cultural competence of future teachers of the humanities [8], in the system of forming the readiness of future foreign language teachers for the use of technological innovations in terms of smart education we identified the following levels: low, medium and high.

Consequently, the functional components of the developed system are represented hierarchically, in accordance with the logic of the educational process and the peculiarities of the preparation of future teachers of a foreign language in the context of smart education. The presented system is also characterized by the presence of an internal organization; subordination and interdependence of the elements; dynamism.

\section{REFERENCES}

1. Bondar, V.I. Didactics: textbook for pedagogical colleges students. Kyiv : Lybid, 2005. P. 264.

2. Honcharova, O.A. Pedagogical conditions of preparing the future foreign language teacher for innovation activity. Diss. Candidate. ped Sciences: Specialist degree 13.00.04 "Theory and methods of vocational education and training". Kyiv: National Linguistic University, 2008. P. 223.

3. Leontiev, A.N. Activity, Consciousness and Personality: electoral collection of psychological works. in 2 volumes. Moscow, 2000. Vol. 2. P. 237.

4. Morska, L.I. Information Technologies in the Study of Foreign Languages: Teach. manual. T.: Aston, 2008. P. 256.

5. Osova, O.O. Ways to Realize the Subject-Subject Interaction in the Process of Teaching Foreign Language Communication
// Journal of Advocacy, Research and Education. 2017. Vol. 4 (1), ss. 3. P. 32-37.

6. Shapar, V. B.,. Rossokha, Shapar, O. V. The newest psychological dictionary/ V. B. Shapar, V. E. Rossokha, O. V. Shapar; under the general editorship of V. B. Shapar. Rostov-onDon : Phoenix, 2005. P. 808.

7. Shtefan, L.V. Formation of innovative culture of future engineers-teachers. Kharkiv: ZEBRA, 2012. P. 348.

8. Shumilova, I.F. Theoretical and methodical foundations of formation of general cultural competence of future teachers of humanities. Diss. EdD: special 13.00.04 "Theory and methods of vocational education"/ H. S. Skovoroda Kharkiv National Pedagogical University, 2016. P. 475. 